\title{
Electrochemical Behavior and Direct Quantitative Determination of Tanshinone IA in Micro-emulsion
}

\author{
Jiao-jiao Wu ${ }^{1,2}$, Wen-ting Wang ${ }^{1,2}$, Miao Wang ${ }^{1,2}$, Hong Liu $^{1,2, *} \&$ Hong-chun Pan ${ }^{1,2, *}$ \\ ${ }^{1}$ College of Pharmaceutical Sciences, Southwest University, Chongqing 400715, China. \\ ${ }^{2}$ Chongqing Engineering Research Center for Pharmaceutical Process and Quality Control, Chongqing \\ 400715, China. \\ *E-mail: 1hphch@126.com, panhongchun216@126.com
}

doi: $10.20964 / 2016.06 .55$

Received: 1 March 2016 / Accepted: 9 April 2016 / Published: 4 May 2016

\begin{abstract}
Tanshinone IA (TAN), an insoluble drug prepared to form micro-emulsion, was electrochemically investigated by cyclic voltammetry (CV) and differential pulse voltammetry (DPV) at glassy carbon electrode. Its electrochemical behavior was proved to be quasi-reversible in acetate buffer (pH4.0), besides, on the basis of $\mathrm{CV}$, the electrochemical redox mechanism of TAN has proved two protons and two electrons involved in the electrode surface reaction. DPV method was developed for its quantitative determination in real sample, and the linear relationship between the peak current and the TAN concentration was obtained in the concentration range of 0.2 to $1.2 \mu \mathrm{g} / \mathrm{mL}$ with a detection limit of $50.25 \mathrm{ng} / \mathrm{mL}$. The reproducibility and repeatability of the method were determined and validated feasibly. The accepted RSD (1.82\%) and recovery studies (96.01-101.23\%) were obtained, and the result was agreed well with that by HPLC. The present study provides guidance for TAN electrochemical behavior investigation and direct determination of micro-emulsion.
\end{abstract}

Keywords: Tanshinone IA, Micro-emulsion, Quantitative determination, Voltammetry, Electrochemical behavior.

\section{$\underline{\text { FULL TEXT }}$}

(C) 2016 The Authors. Published by ESG (www.electrochemsci.org). This article is an open access article distributed under the terms and conditions of the Creative Commons Attribution license (http://creativecommons.org/licenses/by/4.0/). 